\title{
Mudança na prática docente: incentivando o protagonismo
}

\section{discente}

\author{
Cambio en la práctica docente: incentivando el protagonismo discente
}

The change in the docent practice: incentivising the students protagonism

\author{
Ms. Liane N. Much ${ }^{1}$ \\ Kauana M. Bonfada ${ }^{2}$ \\ Eduardo A. Terrazzan ${ }^{3}$
}

\begin{abstract}
Resumo
O presente trabalho caracteriza-se como um relato circunstanciado sobre a prática docente desenvolvida por um dos autores (LNM), que tem por objetivo divulgar uma experiência pedagógica que incentivou o protagonismo de estudantes de uma escola da Educação Básica. Defendemos que para haver efetivas mudanças na educação escolar, faz-se necessário que as práticas docentes ultrapassem a mera transmissão de conteúdos. Com a finalidade de significar os conteúdos, alunos do $8^{\circ}$ e $9^{\circ}$ Anos do Ensino Fundamental de uma Escola Estadual localizada na cidade de Santa Maria/RS, no ano de 2016, foram desafiados a construirem revistas digitais sobre assuntos trabalhados no componente curricular de Geografia, por exemplo, aspectos culturais de povos de diferentes continentes. A atividade proposta logrou êxito, ao perceber-se: (1) o engajamento e cooperação entre os alunos; (2) a criatividade dos trabalhos elaborados; (3) as aprendizagens construídas sobre conteúdos específicos do componente curricular; (4) bem como conhecimentos construídos sobre a utilização de diferentes recursos tecnológicos (programas e ferramentas digitais). Podemos afirmar que essa prática docente foi exitosa, pois permitiu aos educandos se perceberem como protagonistas de suas aprendizagens.
\end{abstract}

Palavras-chave: Prática Docente; Protagonismo Discente; Geografia.

\section{Resumen}

El trabajo actual es caracterizado como un circunstanciado de informe en el ejercicio educativo desarrollado por uno de los escritores (LNM), que tiene para el objetivo que divulgar una experiencia pedagógica que motivó el(la/los/las) de los estudiantes de una escuela del protagonism de educación básico. Defendimos eso allí para ser

\footnotetext{
${ }^{1}$ Aluna do Curso de Doutorado do Programa de Pós-Graduação em Educação (PPGE), do Centro de Educação (CE), da Universidade Federal de Santa Maria (UFSM); Mestre em Educação pela UFSM; Licenciada em Geografia pela Universidade da Região da Campanha (URCAMP); Professora da Rede Pública Estadual na Cidade de Santa Maria/RS; Santa Maria, Rio Grande do Sul, Brasil; E-mail: [lianemuch@gmail.com]. Trabalho apresentado no III Encontro Humanístico Multidisciplinar e II Congresso Latino-Americano de Estudos Humanísticos Multidisciplinares - 3CLAEC, Jaguarão/RS, Brasil, 2017.

${ }^{2}$ Aluna do Curso de Mestrado do Programa de Pós-Graduação em Educação (PPGE), do Centro de Educação (CE), da Universidade Federal de Santa Maria (UFSM); Licenciada em Letras Habilitação Língua Portuguesa e suas Respetivas Literaturas, pela UFSM; Santa Maria, Rio Grande do Sul, Brasil; E-mail: [kauanabonfada@hotmail.com]. Trabalho apresentado no III Encontro Humanístico Multidisciplinar e II Congresso Latino-Americano de Estudos Humanísticos Multidisciplinares - 3CLAEC, Jaguarão/RS, Brasil, 2017.

${ }^{3}$ Professor Associado da Universidade Federal de Santa Maria (UFSM); Doutor em Educação pela Universidade de São Paulo (USP); Bolsista de Produtividade em Pesquisa do CNPq; Coordenador do Grupo de Pesquisas INOVAEDUC/UFSM; Santa Maria, Rio Grande do Sul, Brasil; E-mail: [terraedu@yahoo.com.br]. Trabalho apresentado no III Encontro Humanístico Multidisciplinar e II Congresso Latino-Americano de Estudos Humanísticos Multidisciplinares - 3CLAEC, Jaguarão/RS, Brasil, 2017.
} 
los cambios eficaces en la educación de la escuela, es hecho necesario que las prácticas educativas cruzan la simple transmisión de contenido. Con el propósito de representar los contenido, los estudiantes de los 8th y 9th años de la enseñanza fundamental de uno localizar la escuela de estado federal en Santa Maria / RS de ciudad, en el año de 2016, lo fueron recusar su versión que revistas digitales sobre asignaturas work en el componente curricular de geografía los aspectos por ejemplo, culturales de personas de continentes diferentes. La actividad propuesta consiguió el éxito, when se daba cuenta: (1) la confrontación y la cooperación entre los estudiantes; (2) la creatividad de las obras aclaradas; (3) los learnings se basó en contenido específicos del componente curricular; (4) tan bien como los conocimientos se desarrollaron sobre el uso de diferente tecnológico (programas y herramientas digitales) recursos. Podemos afirmar que esa práctica educativa era exitosa, porque lo permitía a los estudiantes si se dan cuenta como protagonistas de sus learnings.

Palabras-clave: Práctica educativa; Protagonismo Discente; Geografía.

\begin{abstract}
The following article is define as a detailed report about the docent practice developed by one of the authors $(\mathrm{LMN})$, that has the intent of share a pedagogic experience that incentivated the main lead of students from a Basic School. We defend that to have any effective change in the school education, it's needed that the teacher's acts transcend the mere transmission of the school's content. With the purpose to signify those contents, students from the State's Middle School of the city of Santa Maria/RS, were challenged in 2016 to create digitals magazines about subjects studied in the Geography classes - as an example the cultural characteristics of people from different continents. The activity was succeeded when were realised: (1) the commitment e cooperation among students; (2) the creativity input in the task; (3) the learning about the specifics subject of the Component of the Educational System; (4) as well as the knowledge built from the use of different technology tools (programs e digital tools). In conclusion, we affirm that this project was successful, by reason of the allowed of it to students realize their protagonism in their own learning.
\end{abstract}

Keywords: Docent Practice, Student Protagonism, Geography.

\title{
1. Introdução
}

A escola desempenha importante papel na construção do conhecimento e na promoção das aprendizagens dos indivíduos. E, para tornar o processo pedagógico significativo é pertinente que os docentes adotem práticas de ensino diferenciadas e condizentes com as necessidades contemporâneas. Faz-se necessário a superação de muitas das práticas pedagógicas adotadas no século XIX, baseadas na transmissão de informações, pois estas não condizem com a realidade contemporânea, ou seja, não atendem aos anseios e necessidades das atuais gerações,consequentemente pouco contribuem para qualificar o processo de ensino e aprendizagem.

O aluno de hoje questiona, quer saber o porquê de determinados conteúdos, e para quê estes são estudados, qual a contribuição desses conhecimentos para sua vida. Para auxiliar os educandos a construirem suas aprendizagens, os docentes devem ter clareza dos objetivos que pretendem alcançar em suas aulas. Apenas transmitir a informação, não significa que aprendizagem se efetivará.

O presente relato tem por objetivo divulgar uma experiência pedagógica que incentivou o protagonismo de estudantes de uma escola da Educação Básica. A relevância 
deste trabalho está na divulgação de mudanças possíveis e viáveis na prática docente, as quais qualificam o trabalho do professor, favorecendo a construção de conhecimentos pelos alunos.

\section{Necessidade de mudança na prática docente}

A educação escolar ainda desempenha um importante papel na vida das pessoas, tendo entre suas funções contribuir com a socialização do indivíduo, favorecendo-lhe a aprendizagem dos conhecimentos historicamente construídos. Por meio dela deveria ser possível acreditar em um mundo mais fraterno e democrático, com menores índices de desigualdade econômica e social entre as pessoas. Porém na prática isso não é visível, tendo em vista que as instituições escolares ainda produzem e reproduzem ideologias das classes dominantes.

Para que possam ocorrer efetivas mudanças na educação faz-se necessário que as instituições de ensino (escolas, universidades) reavaliem suas ações, para cumprir satisfatoriamente sua função social, que além de orientar para a cidadania, e para o mundo do trabalho, é favorecer a construção dos conhecimentos historicamente produzidos. Porém a mera transmissão de informações, não garante aprendizagens. É tarefa do professor oportunizar situações contextualizadas, significativas e desafiadoras para a construção de conhecimentos pelos alunos, pois informações podem ser adquiridas em diferentes lugares, por meio de diferentes veículos (internet, livros, rádio, televisão, etc), e o acesso a elas, não significa uma construção de conhecimentos. Segundo Porlán, "El professor es el mediador fundamental entre la teoria y la práctica educativa"(1997, p.15).

Para que a aprendizagem realmente se efetive, é necessário que o aluno perceba sentido/significado para tal informação. Para Saviani “A escola, portanto, há de ser criadora o suficiente para, além de transmitir os conhecimentos científicos, dotar o aluno da capacidade de buscar informações, segundo as exigências de sua atividade principal e de acordo com as necessidades do desenvolvimento individual e social" (1994, p.86).

A cada ano, a cada geração de educandos que chegam à escola para aprender formalmente os conhecimentos historicamente acumulados, percebe-se que estas instituições não conseguem cumprir a sua função satisfatoriamente, seja devido à falta de preparo de seus profissionais, seja pela falta de autonomia das instituições, falta de adequação das políticas públicas, ou desmotivação/desilusão dos educandos e da comunidade escolar em buscar e exigir uma educação de qualidade para seus filhos.

Entende-se que as instituições escolares estão vinculadas hierarquicamente a esferas superiores. No caso das escolas públicas estaduais, elas estão vinculadas as coordenadorias 
regionais de educação, e esta a Secretaria de Educação do estado. Muitas das determinações e projetos são definidas nas instâncias superiores, e devem ser executadas pelas instituições de ensino, ou seja, pelas escolas.

Mesmo envolvida com uma série de funções predeterminadas, as escolas têm certo grau de autonomia para realizar o seu trabalho cotidiano, para desenvolver seu projeto junto à comunidade local. O termo autonomia significa, segundo o dicionário Aurélio "1.Faculdade de se governar por si mesmo. 2. Direito ou faculdade que tem uma nação de se reger por leis próprias." (2010,p. 81). A escola além de estar subordinada a legislação federal e estadual, tem autonomia de elaborar normas e leis próprias que a regem e a amparam. Estas geralmente são construídas pela comunidade escolar e documentadas no Regimento Escolar. Nas escolas, o ambiente que oferece maior autonomia para o professor é a sala de aula. Nela o professor tem a oportunidade de desenvolver o seu trabalho fundamentado nos conhecimentos didáticos e pedagógicos que possui, e utilizando-se de diferentes estratégias e metodologias de ensino, para facilitar a construção da aprendizagem dos discentes.

Sabemos que o trabalho docente envolve funções complexas e trabalhosas, pois os educandos da atualidade podem ter acesso às informações em diferentes lugares, e por meios que muitas vezes são mais atrativos do que os encontrados no espaço da sala de aula, se comparados a aulas tradicionais de transmissão passiva de informações, onde o professor passa a aula inteira expondo o conteúdo didático sem possibilitar a interação e interpretação destes por parte dos alunos. Sabe-se que a maioria dos alunos não são autodidatas, ou seja, não conseguem sozinhos construirem suas aprendizagens. Eles necessitam da mediação e incentivo do professor para elaborarem suas aprendizagens. E para favorecer a construção dos conhecimentos dos alunos, o professor precisa utilizar-se de diferentes estratégias de ensino. Para Vieira (2005, p.16) o "termo estratégia de ensino/aprendizagem reporta-se a um conjunto de acções do professor ou do aluno orientadas a favorecer o desenvolvimento de determinadas competências de aprendizagem que se tem em vista".

Entre as estratégias ou metodologias de ensino que podem ser utilizadas em sala de aula para facilitar o processo de ensino/aprendizagem destacam-se: discussão de pequenos grupos; debates; estudo de caso; jogos pedagógicos, dramatizações, estudo orientado em equipes, seminário, exploração de recursos, método de projetos, oficinas, círculo de estudos, pôster, entre outros. Por meio de diferentes estratégias de ensino, é possível desafiar o educando a buscar informações para resolver situações problemas, construindo assim novas aprendizagens. 


\section{Desafiando o protagonismo discente: relato de uma experiência exitosa}

O relato de experiência aqui apresentado, baseou-se em: 1) depoimentos de uma professora; 2) análise de materiais produzidos pelos alunos; 3) e de apontamentos em Diário da Prática Pedagógica (DPP). Porlán defende o uso do DPP como documento para coleta de informações em pesquisa educacional, afirmando que "El Diário deja de ser exclusivamente um registro escrito del processo reflexivo, para converterse progresivamente em el eje organizador de uma autentica investigacón professional” (1997, p.52).

A escola de Educação Básica investigada, da qual resultou o presente trabalho, localiza-se na periferia do município de Santa Maria/RS. Presta serviços educacionais à comunidade local em três turnos de trabalho, a saber: de manhã atendendo as turmas dos anos finais do EF, ( $6^{\circ}$ ao $9^{\text {a }}$ Anos $)$ e ao $1^{\circ}$ Ano do EM; à tarde, os alunos dos Anos Iniciais $\left(1^{\circ}\right.$ ao $5^{\circ}$ Anos) e à noite trabalha com turmas de Ensino Médio ( $\left(1^{\circ}\right.$ ao $3^{\circ}$ Anos $)$, e ainda com turmas da modalidade EJA/EF. Abrangendo um total de 768 alunos matriculados, dados de 2016.

Na disciplina de Geografia, o conteúdo previsto para o $8^{\circ}$ Ano basea-se nos aspectos físicos, sociais e econômicos do continente Americano, e no $9^{\circ}$ Ano, esses mesmos aspectos são estudados nos demais continentes (Europa, Ásia, África, Oceania e Antártida). Tendo em vista a grande quantidade e diversidade de conteúdos para trabalhar em cada ano escolar, a professora desafiou os alunos destas turmas ( 2 turmas de $8^{\circ}$ ano, e 2 turmas de $9^{\circ}$ ano) a realizarem pesquisas bibliográficas e depois construirem revistas digitais, abordando nelas os aspectos culturais, sociais, econômicos e curiosidades sobre o país pesquisado (cada aluno teve a liberdade de escolher um país para a realização do trabalho). "Geografando: conhecendo outros povos e outras culturas", foi a denominação da atividade proposta.

Por meio desta tarefa/desafio, além dos conteúdos previstos no currículo, os alunos tiveram algo para a vida deles, para vivências futuras. Os 43 alunos das turmas do $8^{\circ}$ ano pesquisaram sobre diferentes culturas dos povos do continente americano, e os 43 alunos das turmas de $9^{\circ}$ ano apresentaram resultados de suas pesquisas sobre aspectos culturais de povos localizados nos continentes africano, europeu, asiático e da Oceania.

A coleta de informações sobre o país escolhido deveria ser realizada no contraturno, tendo em vista que a grande maioria dos alunos destas turmas tinham acesso a computadores e internet em suas casas. No entanto, caso o aluno não pudesse realizar a pesquisa em casa, foi oportunizado o acesso à internet na escola, no turno inverso de sua aula. Ficou estipulado um prazo de quinze dias para a coleta das informações iniciais. Após esse prazo, combinou-se uma data em que cada aluno deveria trazer o material pesquisado em dispositivo móvel 
(pendrive, celular, cartão de memória), para que em aula pudessem trabalhar na confecção da revista digital, com o auxílio dos netbooks e/ou computadores que a escola possui.

A segunda etapa deste trabalho foi iniciada na escola. A professora levou os alunos para o Laboratório de Informática, e portando o material pesquisado em dispositivo móvel, cada aluno acessou seu material em um computador/netbook, e por meio de softwares gratuitos iniciaram a confecção de suas revistas digitais. Para a elaboração das revistas alguns elementos deveriam ser incluídos, como: a) cada aluno deveria criar um nome para sua revista; b) identificá-la com seus dados pessoais; c) construir o sumário contendo os assuntos abordados na revista e a respectiva paginação; d) além disso, no corpo do trabalho deveria ter a pesquisa propriamente dita, inserindo-se neste espaço imagens coletadas na internet para ilustrar o trabalho, além de textos produzidos pelos alunos. A criatividade, estética e potencialidade do aluno seria avaliada.

Para a construção do produto final (revista) a professora apresentou e orientou os alunos a utilizarem o software CANVA(www.canva.com). O canva é uma ferramenta gratuita que oferece muitos recursos e layouts para a confecção de diferentes tipos de trabalhos como revistas, livros, folders, capas de trabalhos, cartazes. No entanto, os alunos tiveram a liberdade de escolher a ferramenta que tivessem mais familiaridade para desenvolver seu trabalho individual. O aluno que não quisesse utilizar a referida ferramenta poderia realizar seu trabalho digital utilizando-se do Word ou PowerPoint.

Faz-se necessário informar que o objetivo da professora não era a "decoreba" de informações, mas oportunizar a construção de conhecimentos por meio do auxílio das TICs. Para tal, cada aluno deveria confeccionar uma revista digital utilizando-se de criatividade para organizar a sequência de informações, ou seja, eles seriam os "editores" de suas revistas. A produção da revista poderia ter imagens, poesias, charges, e textos complementares, oriundos da pesquisa realizada anteriormente.

Ao término do trabalho, as revistas foram impressas e apresentadas aos colegas da turma, e no mês de novembro de 2016, as revistas foram divulgadas para a comunidade escolar, no tradicional evento chamado "Mostra Pedagógica", que ocorre anualmente na escola. Na figura a seguir, apresenta-se a capa de um dos trabalhos entregues e apresentados. 
Figura 1 - Exemplo de trabalhos desenvolvidos pelos alunos.

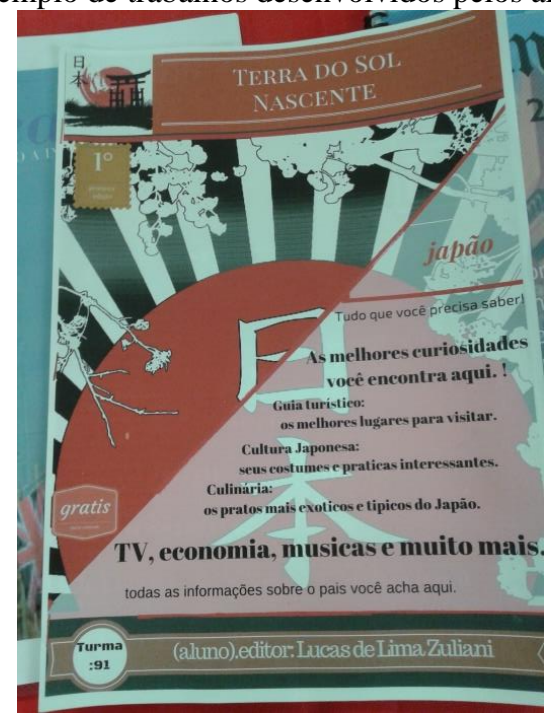

Ao longo do trabalho que durou cerca de 30 dias (8 aulas) surgiram algumas dificuldades/limitações que precisaram ser superadas. Entre as quais destacam-se:

- A lentidão no acesso à internet na escola, onde, para minimizar esta limitação, os alunos foram autorizados a desenvolver o trabalho também em casa;

- Falta de afinidade de alguns alunos com o sistema Canva, a estes foi dada a oportunidade de escolher o software que desejavam utilizar para construir a revista (neste caso, cerca de 25 alunos optaram pelo uso do software MS PowerPoint, mas a grande maioria (61 alunos) aceitou o desafio de utilizar e aprender um novo recurso);

- Dificuldade de muitos alunos em fazer uso de recursos de digitação, inserção e formatação de imagens, que foram superados a partir de orientações do professor e dos colegas que possuiam conhecimentos sobre o uso destes softwares.

A partir da análise e reflexão sobre as demandas surgidas foi possível constatar de que é função do professor encontrar meios de motivar e engajar os alunos no desenvolvimento do trabalho proposto. Mesmo ao planejar atividades para os alunos, faz-se necessário também pensar em alternativas que possam ser usadas caso a proposta de aula ou de atividade não tenha exito, ou caso surjam imprevistos.

\section{Considerações Finais}

A análise feita sobre a ação pedagógica desenvolvida na escola de Educação Básica é um exemplo de que a mudança na prática pedagógica é possível e viável. No entanto exige competência, condições favoráveis de trabalho e ainda comprometimento tanto por parte dos 
professores como por parte dos alunos. Os educandos precisam e merecem uma educação de qualidade, que favoreça o protagonismo discente, e os prepare para o viver em sociedade de modo solidário e consciente. A aprendizagem se efetiva quando o aluno percebe sentido e significado nas informações recebidas.

O objetivo de desafiá-los (os discentes) a produzirem algo educativo foi alcançado com êxito, visto que cada aluno produziu a sua revista, utilizando-se de diferentes ferramentas para cumprir a tarefa. Durante as apresentações de trabalho entre os alunos, e ainda para a comunidade escolar na Mostra Pedagógica, ficou claro que os alunos foram além das pesquisas inicialmente previstas, fazendo novas investigações e analisando até mesmo aspectos de outras nações, permitindo assim aumentar o interesse, as curiosidades e a criatividade dos mesmos. Da mesma maneira, a troca de informações entre os alunos foi muito interessante, porque os motivou a investigarem mais e a interagirem entre si, onde o colega que sabia mais ajudava o que sabia menos.

A partir do relato aqui apresentado, constatou-se que por meio de práticas inovadoras e contextualizadas, os professores conseguem atrair a atenção dos alunos, favorecendo as aprendizagens dos discentes. No entanto, um elemento de fundamental importância que deve ser levado em conta para a mudança de práticas pedagógicas relaciona-se as condições de trabalho do docente. Este precisa de tempo para planejar diferentes estratégias de aulas, oportunidade de espaço para trocar experiências e ideias com colegas, pois muitas vezes a integração de diferentes disciplinas, o que enriqueceria ainda mais o trabalho docente nas escolas, ainda não ocorre por falta de comunicação entre seus respectivos professores. Além disso, a disponibilidade de recursos materiais para realizar trabalhos diferenciados também contribui para a implantação de propostas inovadoras. No caso das revistas, alguns alunos não tinham condições financeiras para mandar imprimir e encadernar seus trabalhos, e infelizmente a escola não oferece esse tipo de apoio aos alunos, tendo em vista que não possui máquina de xérox na instituição, o que dificulta alguns trabalhos. E para não excluir o trabalho do aluno, a professora auxiliou imprimindo o trabalho com recursos financeiros próprios.

\section{Referências}

FERREIRA, Aurélio Buarque de Holanda. Mini Aurélio: dicionário de língua portuguesa. 8 ed. Curitiba: Positivo, 2010.

LIBÂNEO, José Carlos. Pedagogia e pedagogos, para quê?? 4. ed. São Paulo: Cortez Editora, 2010. 
PORLÁN, Rafael, MARTÍN, José. El Diário del Profesor: um recurso par la investigación em el aula. Sevilla,PRT;Díada, 4ed, 1997.

SAVIANI, Nereide. Saber escolar, currículo e didática: problemas da unidade conteúdo/método no processo pedagógico. Campinas: Autores Associados,1994.

VIEIRA, Rui Marques, VIEIRA, Celina. Estratégias de Ensino/Aprendizagem: o questionamento promotor do pensamento crítico. Lisboa: Instituto Piaget.2005. 